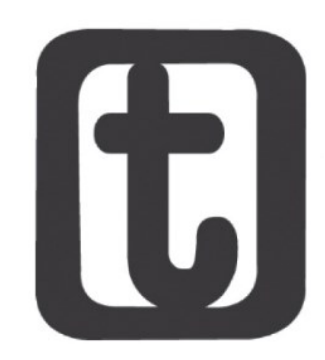

\title{
SERVIÇO SOCIAL E EDUCAÇÃO PERMANENTE: INTERFACE ENTRE PRECEPTORIA E FORMAÇÃO EM SAÚDE
}

Social work and permanent education: interface between preceptorship and health training

\author{
Joyce Helena Martins Leal* \\ Ana Claudia Correia Nogueira** \\ Fernando Lopes Tavares de Lima***
}

\begin{abstract}
RESUMO
O trabalho aborda reflexões sobre a experiência dos preceptores de Serviço Social no Programa de Residência Multiprofissional em Oncologia (PRMO) do Instituto Nacional de Câncer José Alencar Gomes da Silva (INCA). Objetiva compreender, sob a ótica dos assistentes sociais preceptores, como o PRMO do INCA tem contribuído para o processo de formação e educação permanente dos assistentes sociais. Realizou-se uma pesquisa quanti-qualitativa, por meio de questionário semiestruturado aplicado a 31 assistentes sociais preceptores e de grupo focal com participação de 04 membros da Comissão de Ensino do Serviço Social. Utilizou-se o referencial teórico do materialismo histórico-dialético, considerando a compreensão da dinâmica social a partir da totalidade. $O$ texto está dividido em dois eixos analíticos: (1) aspectos conceituais relativos a Política de Educação Permanente e o Serviço Social na Residência Multiprofissional; (2) perfis acadêmico e profissional dos preceptores e as reflexões sobre as potencialidades, limites e desafios da formação em saúde. Os resultados sinalizam que a residência constitui um importante espaço de formação profissional para os assistentes sociais, considerando a perspectiva do Projeto Ético Político. Frente aos desafios cotidianos dos serviços de saúde, faz-se necessário pensar em novos horizontes para a consolidação da residência, enquanto estratégia de qualificação da assistência aos usuários.
\end{abstract}

\section{PALAVRAS-CHAVE}

Formação Profissional. Serviço Social. Educação Permanente. Residência Multiprofissional.

\section{ABSTRACT}

This work presents reflections on the experience of Social Service preceptors in the Multiprofessional Oncology Residency Program (MORP) of the National Cancer Institute José Alencar Gomes da Silva (INCA).

\footnotetext{
* Assistente Social. Especialista em Residência Multiprofissional em Oncologia e Gestão Pública Municipal e Serviço Social e Políticas Sociais. Residente Multiprofissional em Serviço Social no Instituto Nacional do Câncer (INCA, Rio de Janeiro, Brasil). Praça Cruz Vermelha, 23, 4 andar, Centro, Rio de Janeiro (RJ), CEP.: 20230-130. E-mail: <joyce.leal@hotmail.com>.

** Assistente social. Mestre em Política Social. Coordenação de Serviço Social (HCII). Instituto Nacional de Câncer José Alencar Gomes da Silva. Hospital do Câncer II. Instituto Nacional do Câncer José Alencar Gomes da Silva. (INCA, Rio de Janeiro, Brasil). Praça Cruz Vermelha, 23, $4^{\circ}$ andar, Centro, Rio de Janeiro (RJ), CEP.: 20230130. E-mail: <anogueira@inca.gov.br>.

*** Dentista. Mestre em Saúde Pública. Tecnologista programas educacionais em saúde do Instituto Nacional do Câncer José Alencar Gomes da Silva. (INCA, Rio de Janeiro, Brasil). Praça Cruz Vermelha, 23, $4^{\circ}$ andar, Centro, Rio de Janeiro (RJ), CEP.: 20230-130. E-mail: <flima@inca.gov.br>.
}

DOI 10.22422/temporalis.2018v18n36p379-396 
It aims to understand, from the perspective of preceptors social workers, how INCA's MORP has contributed to the process of formation and permanent education of social workers. A quantitative-qualitative research was carried out through a semi-structured questionnaire applied to 31 preceptor social workers and a focus group with the participation of 04 members of the Social Work Teaching Commission. Theoretical reference of historical-dialectical materialism was used, considering the understanding of the dynamics from the social totality. This text is divided into two analytical axes: (1) conceptual aspects related to the Permanent Education Policy and Social Work in the Multiprofessional Residence; (2) academic and professional profiles of preceptors and reflections on the potential, limits and challenges of health education. The results indicate that the residence constitutes an important space for professional training for social workers, considering the perspective of the Political Ethical Project. Faced with the daily challenges of the health services, it is necessary to think of new horizons for the consolidation of the residence as strategy of qualification of the assistance to the users.

\section{KEYWORDS}

Professional Training. Social Work. Permanent Education. Multiprofessional Residence.

Submetido em: 25/7/2018.

Aceito em: 12/12/2018.

\section{INTRODUÇÃO}

A Residência Multiprofissional em Saúde é definida como pós-graduação lato sensu, caracterizada pelo ensino em serviço, sob regime de dedicação exclusiva em 60 horas semanais e duração mínima de dois anos, com $80 \%$ de estratégias educacionais práticas e teórico-práticas e $20 \%$ de atividades teóricas. Essa modalidade de formação é destinada às categorias profissionais da saúde, excetuando a Medicina, e busca materializar os princípios e diretrizes do Sistema Único de Saúde na formação da força de trabalho. (BRASIL, 2005; BRASIL, 2009).

No Instituto Nacional de Câncer José Alencar Gomes da Silva (INCA), o Programa de Residência Multiprofissional em Oncologia (PRMO) foi implementado em 2010, com o objetivo de qualificar profissionais para atuarem na rede de atenção à saúde, considerando a integração das atividades de assistência, ensino, pesquisa e gestão na construção de um perfil profissional crítico, propositivo e reflexivo.

Além do Serviço Social, o PRMO é composto pela Enfermagem, Farmácia, Fisioterapia, Nutrição, Psicologia e Odontologia (INSTITUTO NACIONAL DE CÂNCER JOSÉ ALENCAR GOMES DA SILVA, 2018). A residência multiprofissional foi implementada em 2010, porém desde 1988 o Serviço Social desenvolvia atividades de ensino, ofertando cursos de atualização para os assistentes sociais da rede. Nos anos 2000, a instituição passou a oferecer especialização lato sensu em Serviço Social e Oncologia (CHALUB; SKABA, 2003), considerando o amadurecimento da categoria, sobretudo na docência, no processo de formação em saúde para os (as) assistentes sociais da rede, tendo em vista as experiências adquiridas nos cursos de capacitação e atualização.

Diferente da formação tradicional oferecida na modalidade de especialização uniprofissional, organizada em disciplinas isoladas, o programa de residência visa propiciar a interlocução multidisciplinar das diversas áreas do conhecimento, com o propósito de uma formação integrada e em perspectiva interdisciplinar. 
Atualmente, o INCA possui 37 assistentes sociais distribuídas (os) nas 5 unidades hospitalares: 14 no Hospital do Câncer I $(\mathrm{HCl}) ; 8$ no Hospital do Câncer II (HCII); 4 no Hospital do Câncer III (HCIII); 9 Hospital do Câncer IV (HCIV); e 2 no Centro de Transplante de Medula Óssea (CEMO). Em todas as unidades assistenciais do INCA, esses profissionais desenvolvem alguma atividade de ensino na residência, especialmente na preceptoria. Raros são os profissionais que não participam do programa e/ou não estão envolvidos com alguma atividade de ensino, apesar de, contraditoriamente, não se ter uma carga horária definida institucionalmente para o desenvolvimento das atividades de ciência e tecnologia.

De acordo com os parâmetros para atuação de assistentes sociais na saúde, o profissional deve "[...] participar ativamente dos programas de residência, desenvolvendo ações de preceptoria, coordenação, assessoria ou tutoria, contribuindo para qualificação profissional da equipe de saúde e dos assistentes sociais, em particular" (CONSELHO FEDERAL DE SERVIÇO SOCIAL, 2011, p. 64).

Nesse estudo, destaca-se o papel da preceptoria como elemento fundamental para o exercício crítico do processo de ensino-aprendizagem. De acordo com o Artigo $13^{\circ}$ da Resolução CNRMS - n 2, de 2012: "[...] a função de preceptor caracteriza-se por supervisão direta das atividades práticas realizadas aos residentes nos serviços de saúde em que se desenvolvem o programa, exercida por profissional vinculado à instituição formadora ou executora, com formação mínima de especialista" (BRASIL, 2012, não paginado, grifo nosso).

Apesar dessa definição normativa, é fundamental debater sobre os limites e desafios da prática cotidiana dos preceptores, buscando fomentar uma reflexão crítica acerca do papel político-pedagógico desses profissionais no desenvolvimento dessa função, considerando as dimensões técnico-operativa, teórico-metodológica e ético-política da profissão. Portanto, o preceptor deve atuar não apenas na formação técnica, mas também ética do residente, o que exige construir um diálogo permanente no sentido de superar os tensionamentos provenientes do exercício profissional (MONTEIRO, 2015).

Seguindo essa linha, objetiva-se com esse trabalho compreender, sob a ótica dos assistentes sociais preceptores do INCA, como o programa de residência multiprofissional tem contribuído para o processo de formação e educação permanente dos assistentes sociais.

\section{METODOLOGIA}

Trata-se de uma pesquisa quanti-qualitativa baseada na perspectiva dialética do materialismo histórico. Segundo Gil (2008), a dialética fornece as bases para uma interpretação dinâmica e totalizante da realidade social. Ou seja, os fatos sociais não são entendidos isoladamente, abstraídos de suas influências políticas, econômicas, culturais, mas na sua totalidade. Nessa perspectiva, busca-se pistas e conexões para problematizar a temática do ensino em serviço, tendo os preceptores como participantes centrais nesta pesquisa.

A utilização das abordagens quantitativas e qualitativas visa complementar a análise da realidade social, haja vista que o "[...] conjunto de dados quantitativos e qualitativos se 
complementam, pois a realidade abrangida por eles interage dinamicamente, excluindo qualquer dicotomia" (MINAYO, 2001, p. 22, grifo nosso).

Para identificar os perfis acadêmico e profissional dos assistentes sociais preceptores, foi aplicado um questionário semiestruturado, composto por 19 questões. Dos 37 entrevistados, apenas 05 profissionais não participaram da pesquisa, por motivo de férias ou licenças.

Para aprofundar a discussão da temática, optou-se por um grupo focal com quatro representantes da Comissão de Ensino de Serviço Social do INCA. O grupo foi conduzido por 02 pesquisadores, que esclareceram o objetivo da proposta e viabilizaram a interlocução entre os participantes e a temática. Utilizando-se de um roteiro, o grupo focal buscou identificar as potencialidades, os limites e desafios do PRMO no ensino-serviço para a categoria profissional.

A análise dos dados quantitativos foi realizada por meio de estatística descritiva (medidas de tendência central e de frequência), com o uso do programa Excel. Já os dados qualitativos foram constatados por meio da análise de conteúdo, conforme descrito por Bardin (2009.

Os resultados foram organizados em dois eixos analíticos. Primeiro buscou-se contextualizar o Serviço Social e sua relação com a educação permanente. No segundo eixo, no entanto, apresentou-se o perfil profissional e as formas de atuação docente no INCA.

Os estudos respeitaram os aspectos éticos em pesquisa e foram aprovados pelo Comitê de Ética em Pesquisa da instituição, sob o número CAAE 71690817.1.0000.5274.

\section{EDUCAÇÃO PERMANENTE E SERVIÇO SOCIAL NOS PROGRAMAS DE RESIDÊNCIA MULTIPROFISSIONAL}

A Política Nacional de Educação Permanente do SUS, instituída pela Portaria 198/2004 e endossada na Portaria de Consolidação $n^{\circ} 2 / 2017$, tem como conceito norteador a aprendizagem por meio do trabalho. Por isso:

\footnotetext{
Propõe-se que os processos de capacitação dos trabalhadores da saúde tomem como referência as necessidades de saúde das pessoas e das populações, da gestão setorial e do controle social em saúde, tenham como objetivos a transformação das práticas profissionais e da própria organização do trabalho e sejam estruturados a partir da problematização do processo de trabalho (BRASIL, 2017, não paginado).
}

Com a institucionalização da Política Nacional de Educação Permanente, em 2004, a formação e desenvolvimento de trabalhadores para o setor ganhou status de política pública. Sabe-se que o investimento na formação dos trabalhadores da saúde é uma demanda antiga, defendida pelo Movimento Sanitário dos anos 1980. No entanto, diante das investidas da ofensiva neoliberal nas políticas públicas, especialmente na saúde, essa temática passa a incorporar um discurso enviesado, responsabilizando somente o 
trabalhador pela sua qualificação/capacitação para transformação das práticas na saúde e da própria organização do trabalho - sem discutir a macroestrutura do sistema, isentando o Estado de cumprir o papel de indutor desse processo.

Segundo Carotta, Kawamura e Salazar (2009), a Política Nacional de Educação Permanente do SUS é um instrumento que tem direcionado ações de saúde mais progressistas, através da transformação das práticas em saúde por meio da transversalidade. Por sua vez, cabe destacar que em muitos casos, no cotidiano da saúde, não se identificam condições objetivas para os trabalhadores desenvolverem essa educação de forma plena, considerando a intensa precarização das condições de trabalho.

No âmbito do Serviço Social, a Política de Educação Permanente do Conselho Federal de Serviço Social e Conselho Regional de Serviço Social (CFESS/CRESS) de 2012 objetiva direcionar uma formação profissional para além da qualificação e atualização, sendo um processo, portanto, de reflexão do cotidiano, da realidade social de forma crítica e propositiva, na perspectiva da transformação social. Deste modo,

[...] pensar a educação permanente no Serviço Social pressupõe, portanto, afirmar o projeto profissional, articulando uma dupla dimensão: de um lado, as condições macrossocietárias que estabelecem o terreno sócio-histórico em que se exerce a profissão, seus limites e possibilidades; e, de outro, as respostas de caráter ético-político e técnico-operativo dos/as agentes profissionais a esse contexto, apoiadas nos fundamentos históricos, teóricos e metodológicos do Serviço Social (CONSELHO FEDERAL DE SERVIÇO SOCIAL, 2013, P. 8).

Essa direção crítica coaduna a perspectiva apontada por Guerra (2013), ao discutir o significado do $10^{\circ}$ princípio estabelecido no Código de Ética da profissão quanto ao “[...] compromisso com a qualidade dos serviços prestados à população e com o aprimoramento intelectual, na perspectiva da competência profissional" (GUERRA, 2013, p. 124). Logo, se trata de um processo que envolve necessárias problematizações acerca das condições objetivas e subjetivas do exercício profissional. Para Guerra (2013):

[...] a capacitação contínua e permanente proposta no código de ética profissional não se trata da promoção recorrente e sistemática atualização profissional, mas sim uma formação que habilite o profissional tanto a fazer a crítica da racionalidade posta na educação da qual sua formação é resultado, quanto se lhe exige o aprimoramento dos seus conhecimentos numa determinada direção (GUERRA, 2013, p. 128).

No bojo dessa discussão, é importante ressaltar também a diferença entre os conceitos de Educação Permanente e Educação Continuada. O primeiro compreende o contexto histórico, político e econômico e considera as transformações societárias e os interesses vigentes das classes sociais. Nesta perspectiva, "[...] a Política de Educação Permanente extrapola a formação voltada para a qualificação do exercício profissional, podendo alcançar a dimensão mais ampla da organização política da categoria" (CONSELHO FEDERAL DE SERVIÇO SOCIAL, 2013, p. 13). Portanto é preciso diferenciar, entendendo que o segundo conceito está relacionado "[...] ao prosseguimento da formação inicial, objetivando o aperfeiçoamento profissional, o que nem sempre modifica e qualifica as estruturas e os processos de trabalho" (CONSELHO FEDERAL DE SERVIÇO SOCIAL, 2012, p.18). 


\begin{abstract}
Neste sentido, vale indicar que esta proposta de Política de Educação Permanente se contrapõe à lógica instrumental abstrata, do chamado Capital Humano, tão difundido pelo modelo de acumulação flexível e reforçado no ideário neoliberal, que reduz a noção de formação continuada a um conjunto de treinamentos esparsos, para atender às demandas mais imediatas do mercado. Sob o argumento de valorização do conhecimento, exige-se do/a trabalhador/a processos contínuos de reciclagens e aprendizados que, nesta tese, os/as torna 'aptos/as' a assimilar rapidamente novas formas de controle e gestão dos processos de trabalho, cada vez mais atomizados e fluidos, característicos da chamada produção flexível (CONSELHO FEDERAL DE SERVIÇO SOCIAL, 2013, p. 22).
\end{abstract}

De modo geral, tanto a Política Nacional de Educação Permanente do SUS quanto a Política de Educação Permanente do CFESS/CRESS orientam uma formação crítica, comprometida com a qualificação dos serviços prestados aos usuários da saúde. Ao incorporar o serviço como eixo central da produção do conhecimento, essa configuração passa a demandar dos programas de residência o estreitamento da relação ensino em serviço, o que reafirma o intrínseco paralelismo entre formação e exercício profissional. Elas podem servir como instrumentos que possibilitam o entendimento de que a formação "[...] é um processo permanente de qualificação e atualização, porque exige deciframento cotidiano da realidade social." (CFESS, 2013 p. 19-20).

Lobato (2010) afirma que as residências se encontram atreladas a um contexto de grandes disputas, lutas políticas e sociais, exigindo que os sujeitos envolvidos assumam posição de protagonistas deste processo. Esse é um fato, a residência está imersa na contradição da luta de classes, como fruto das relações sociais.

Não obstante, Silva e Brotto (2016) questionam se as residências multiprofissionais fazem parte de uma estratégia que visa estruturar a rede de saúde, através da oferta de um campo de prática precarizado para os profissionais, haja vista que se estabelece uma forma de contrato aviltante, temporário e precário. Segundo os autores, isso reflete a intensificação da precarização das condições de trabalho na sociedade capitalista periférica.

Devido a isso, é necessário incorporarmos os valores e princípios do Projeto de Reforma Sanitária e do Projeto Ético Político profissional no direcionamento dos programas de residência, pois são esses dois projetos importantes que direcionam o trabalho do assistente social na saúde (BRAVO; MATOS, 2006).

Cabe ressaltar que há importantes avanços nas discussões teóricas sobre a residência nos últimos anos, como por exemplo, a organização do I Seminário Nacional Residência em Saúde e Serviço Social, em 2016; e a publicação do documento Residência em Saúde e Serviço Social: subsídios para reflexão, em 2017. Nesta esteira de pensamento, o artigo ora proposto pretende contribuir com essa discussão a partir da experiência do Serviço Social de uma instituição de referência, situada no RJ. 


\section{PERFIL PROFISSIONAL E ATUAÇÃO DOCENTE NO INCA: REFLEXÕES SOBRE A REALIDADE}

Dos 31 assistentes sociais preceptores participantes, 30 são mulheres, fato que corrobora com a tendência histórica da profissão quanto à predominância do sexo feminino. Os participantes possuem idades entre 32 a 55 anos e, em média, 16 anos da conclusão da graduação (variação entre 7 e 33 anos). O tempo médio de atuação como assistente social é de 15,4 anos, sendo de 13,2 na área da saúde. O tempo médio de atuação como preceptor no INCA é de 5,9 anos, o que representa um grupo experiente.

Foi identificado que $42,2 \%$ encontram-se exercendo sua atividade laborativa no $\mathrm{HCl} ; 22,5 \%$ no HCII; $19,3 \%$ no HCIV; 9,6\% no HCIII; e 6,4\% no CEMO. Todos possuem vínculo estatutário, sendo um grande percentual ingresso pelos dois últimos concursos públicos realizados (2011 e 2014). No último concurso público, foram disponibilizadas 07 (sete) vagas para tecnologista pleno, sendo exigidos como requisitos mínimos: título de mestre, seja em Serviço Social, Saúde ou Políticas Sociais; ou então ter, pelo menos, 3 (três) anos de experiência comprovada na área de atuação. Percebe-se que no processo de seleção é almejado um determinado perfil profissional que reafirma a importante interlocução entre as ações de pesquisa, assistência, gestão e ensino, do qual se destaca a inserção dos assistentes sociais no processo de preceptoria. A Tabela 1 apresenta o perfil acadêmico do grupo participante:

Tabela 1: Perfil acadêmico dos assistentes sociais preceptores do INCA, 2017.

\begin{tabular}{|c|r|}
\hline Graduação & $6(19,3 \%)$ \\
\hline Privada & $25(80,7 \%)$ \\
\hline Pública & $23(74,2 \%)$ \\
\hline Especialização & $8(25,8 \%)$ \\
\hline Sim & $3(09,6 \%)$ \\
\hline Não & $28(90,4 \%)$ \\
\hline Residência & $22(70,9 \%)$ \\
\hline Sim & $9(29,1 \%)$ \\
\hline Não & $2(06,4 \%)$ \\
\hline Mestrado & $29(93,6 \%)$ \\
\hline Sim & $1(03,3 \%)$ \\
\hline Não* & $30(96,7 \%)$ \\
\hline Doutorado & \\
\hline Sim & \\
\hline Não* & \\
\hline Pós-doutorado & \\
\hline Sim & \\
\hline Não & \\
\hline
\end{tabular}

*5 (cinco) profissionais com mestrado e com doutorado em andamento.

A pesquisa identificou um perfil de profissionais que buscam a permanente qualificação, o que corrobora com a direção dada pelo Código de Ética Profissional do Serviço Social quanto ao direito ao aprimoramento profissional de forma contínua. Conforme afirmou Guerra (2013), essa direção é parte do compromisso sócio-profissional e político da categoria, que deve buscar a qualidade dos serviços prestados à população, considerando o aprimoramento intelectual na perspectiva do exercício da competência profissional. 
Não obstante, as exigências da sociedade capitalista têm demandado cada vez mais um profissional qualificado, com perfil polivalente para atender as necessidades e reprodução do capital. Nesse sentido, lamamoto ressalta que:

\begin{abstract}
A mercantilização da força de trabalho do assistente social, pressuposto do estatuto assalariado, subordina esse trabalho de qualidade particular aos ditames do trabalho abstrato e o impregna dos dilemas da alienação, impondo condicionamentos socialmente objetivos à autonomia do assistente social na condução do trabalho e à integral implementação do projeto profissional (IAMAMOTO, 2007, p. 416).
\end{abstract}

Assim, ao pensarmos na qualificação desse profissional, não podemos desconsiderar que este está inserido na lógica de produção e reprodução do capital, sendo profissional assalariado. A qualificação almejada não deve se limitar aos aspectos tecnicistas e produtivistas, mas considerar o desenvolvimento de uma perspectiva crítica e reflexiva que visa a superação do status quo. Deve-se ter em vista as três dimensões da intervenção profissional, quais sejam: teórico-metodológica, técnico-operativa e ético-política.

No INCA, instituição onde os trabalhadores integram a carreira de ciência e tecnologia, o incentivo dado pelo plano de cargos, carreira e salários, também estimula o aprimoramento contínuo, o que dá margem para que os profissionais busquem capacitações lato e stricto sensu, de modo a potencializar um corpo profissional diferenciado. Cabe destacar, entretanto, que apesar da estrutura institucional do INCA, esses trabalhadores também são afetados pelas precarizações das relações de trabalho, como por exemplo: a extensa carga horária de 40 horas semanais de trabalho em detrimento das 30 horas da categoria.

Um outro ponto a destacar é a ausência de uma carga horária definida para o desenvolvimento das atividades de ensino e pesquisa, havendo uma sobrecarga das atividades assistenciais. Assim, a atuação dos assistentes sociais se dá, majoritariamente, no âmbito das enfermarias e nos ambulatórios. A gestão é outro desafio para o assistente social, principalmente ao considerar as diversas inserções dos profissionais no processo de trabalho coletivo em saúde.

Somando-se a isso, cabe uma reflexão acerca dos espaços existentes no INCA com o intuito de promoverem a qualificação dos profissionais para o exercício das atividades docentes (Tabela 2).

Tabela 2: Qualificação para atuação docente no programa de residência multiprofissional.

\begin{tabular}{|l|r|}
\hline Fez curso de formação para docência & $18(57,8 \%)$ \\
\hline Não & $13(42,2 \%)$ \\
\hline Sim & $22(70,9 \%)$ \\
\hline Não & $9(29,1 \%)$ \\
\hline Sim & $17(54,9 \%)$ \\
\hline Fez algum curso de formação para tutoria EAD & $14(45,1 \%)$ \\
\hline Não & \\
\hline Sim & $11(35,5 \%)$ \\
\hline Fez algum curso para preceptoria & $20(64,5 \%)$ \\
\hline Não & \\
\hline Sim & \\
\hline
\end{tabular}

EAD: Educação a distância 
Conforme apresentado, $64,5 \%$ dos profissionais já realizaram o curso específico para preceptoria ofertado pelo INCA, desde 2014. Um número menor, porém, significante, realizou curso de formação para docência (42,2\%). O investimento na qualificação dos profissionais para o exercício da docência é extremamente relevante numa instituição de ciência e tecnologia, como o INCA, uma vez que os assistentes sociais das unidades atuam como professores e orientadores de alunos, dentre outras atividades inerentes ao exercício da docência. Destaca-se a importância da docência enquanto um processo contínuo de construção de conhecimentos, que possibilita intercâmbio de ideias e troca de experiências. Portanto, um maior investimento institucional para a ampliação da participação dos profissionais na formação em docência é fundamental para qualificar a EPS.

Alguns preceptores fizeram também os cursos para conteudista $(29,1 \%)$ e tutoria $(45,1 \%)$ para as atividades de educação a distância (EAD). As atividades de EAD têm sido utilizadas, estrategicamente, como ferramentas complementares das atividades teórico-práticas dos residentes, visando, ao mesmo tempo, aprofundar o estudo acerca das temáticas afetas à intervenção profissional e, paralelamente, ampliar os espaços de discussão e compor a carga horária exigida pelo programa de residência.

Para Chalub; Skaba, (2003):

A construção do conhecimento em Serviço Social reflete a demanda da sociedade e o projeto de formação profissional, tanto no nível da graduação quanto da pósgraduação (stricto e lato sensu). [...] Nesta lógica, finalizamos acentuando que todo o trabalho do Serviço Social em Saúde só se justifica se tem por objetivo a qualificação do atendimento prestado aos seus usuários (CHALUB; SKABA, 2003, p. 40-45).

É possível, portanto, apreender que a educação permanente, em suas mais variadas formas de materialização, beneficia os diferentes sujeitos envolvidos nas práticas cotidianas do instituto, sejam eles gestores, profissionais, residentes ou usuários.

Percebe-se que há um esforço institucional em possibilitar a qualificação de preceptores, seja através de cursos específicos relacionados a essa função, ou por meio de espaços de discussão e construção coletiva do programa multiprofissional, a saber: as reuniões mensais da COREMU e a avaliação anual do programa, além da discussão dos módulos e dos campos práticos, realizadas pelo Serviço Social. Todavia, são necessárias ampliações desses espaços, em decorrência da necessidade de disponibilização de condições objetivas para que os profissionais possam conciliar suas atividades assistenciais com a participação nos cursos oferecidos pela instituição, considerando o retorno dessa qualificação para as diversas atividades profissionais (na assistência, na pesquisa, no ensino e na gestão).

O PRMO, dentro dos seus objetivos, tem afirmado a importância de concretizar espaços propositivos no sentido de corroborar a reflexão crítica, potencializando os sujeitos que dele participam. Isso parece superar parte do desafio (identificado em estudo anterior) de se garantir a educação permanente para os preceptores (SILVA; MONTEIRO; SANTO; MELO; ESTALINO, 2012). As seguintes contribuições dos profissionais participantes do grupo focal oferecem subsídios para essa reflexão. 
Hoje eu percebo nesses sete anos de trajetória, que a educação permanente para o preceptor inicia um processo de qualificação. Através dos cursos de preceptoria, de tutoria, de conteudista. No início a gente foi elencado e intitulado como preceptor sem ter uma preparação. Alguns já tinham aproximação com universidade, com ensino, pela sua trajetória profissional, mas não tinha essa oferta que hoje o INCA já consegue. (Entrevistada 1)

Hoje no INCA está se pensando, inclusive a organização do seu projeto político pedagógico. Isso é um outro elemento importante para se pensar uma Política de Educação Permanente. (Entrevistada 2)

Tem uma equipe pedagógica que pode estar ajudando a construir os cursos EAD, recursos institucionais, formação de preceptores. Vai ter um outro agora para docentes... [...] é um construir a habilidade de ser preceptor fazendo (Entrevistada 4).

A preceptoria foi destacada como um elemento diferenciador para qualificação do corpo docente-assistencial, como um espaço de troca de saberes e amadurecimento profissional:

Vivencia-se muito a questão do amadurecimento não só dos residentes mas também dos profissionais preceptores que estão diretamente com esse residente (Entrevistada 3)

Acho que a proposta da residência, em qualquer instituição, é desenvolver habilidades, competências e atitudes, não só para o discente. Nesse processo, o preceptor também constrói isso tendo sempre a prática como a instância que vai ofertar situações problemas para o aprendizado dos dois (Entrevistada 4).

A residência é perceptivelmente destacada por sua contribuição no desenvolvimento dos conhecimentos, das habilidades e das atitudes para uma intervenção profissional fundamentada numa análise crítica. Percebe-se que os assistentes sociais identificam o avanço que o PRMO trouxe para o espaço institucional, especialmente na qualificação do corpo docente. Entretanto, algumas dificuldades foram elencadas, como a multiplicidade de funções assumidas pelos preceptores no desenvolvimento das atividades de ensino; o que caracteriza, por um lado, a inserção em diversos espaços de interlocução; e, por outro, uma possível sobrecarga de trabalho (Tabela 3).

Tabela 3: Atuação dos preceptores nas atividades de ensino desenvolvidas na instituição.

\begin{tabular}{|l|r|}
\hline Representante na COREMU1 & $8(25,8 \%)$ \\
\hline Atua/Já atuou & $23(74,2 \%)$ \\
\hline Não & \\
\hline Representante Comissão de Ensino ${ }^{2}$ & \\
\hline
\end{tabular}

\footnotetext{
${ }^{1}$ A COREMU é instância de caráter deliberativo e tem como atribuições: a) Coordenação, organização, articulação, supervisão, avaliação e acompanhamento dos Programas de Residência em Área Profissional da Saúde da instituição proponente. b) Acompanhamento do plano de avaliação de desempenho dos profissionais de saúde residentes. c) Definição de diretrizes, elaboração de editais e condução do processo seletivo de candidatos. (BRASIL, 2015)

${ }^{2}$ À Comissão de Ensino cabe: I - acompanhar a execução do Projeto Pedagógico, propondo ajustes e mudanças às coordenações dos programas; II - assessorar as coordenações dos programas no processo de planejamento, implementação, acompanhamento e avaliação das ações do desenvolvimento do programa, propondo ajustes e mudanças; III - promover a institucionalização de novos processos de gestão, atenção e formação em saúde, visando ao fortalecimento ou à construção de ações integradas em oncologia, entre equipe, entre serviços e nas redes de atenção do SUS; IV - estruturar e desenvolver grupos de estudo e de
} 


\begin{tabular}{|l|r|}
\hline Atua/Já atuou & $17(54,9 \%)$ \\
\hline Não & $14(45,1 \%)$ \\
\hline Coordenador modulo eixo específico & $17(54,9 \%)$ \\
\hline Atua/Já atuou & $14(45,1 \%)$ \\
\hline Não & $5(16,1 \%)$ \\
\hline Coordenador de modulo do eixo transversal & $26(83,9 \%)$ \\
\hline Atua/Já atuou & \\
\hline Não & $14(45,1 \%)$ \\
\hline Docente do eixo transversal & $17(54,9 \%)$ \\
\hline Atua/Já atuou & $28(90,4 \%)$ \\
\hline Não & $3(09,6 \%)$ \\
\hline Docente do eixo específico & $15(48,5 \%)$ \\
\hline Atua/Já atuou & $16(51,5 \%)$ \\
\hline Não & $11(35,5 \%)$ \\
\hline Tutor & $20(64,5 \%)$ \\
\hline Atua/Já atuou & $3(09,6 \%)$ \\
\hline Não & $28(90,4 \%)$ \\
\hline Conteudista EAD & $13(42,2 \%)$ \\
\hline Atua/Já atuou & $18(57,8 \%)$ \\
\hline Não & \\
\hline Tutor EAD & \\
\hline Atua/Já atuou & \\
\hline Não & \\
\hline Orientador de TCR & \\
\hline Atua/Já atuou & \\
\hline Não & \\
\hline & \\
\hline
\end{tabular}

COREMU: Comissão de Residência Multiprofissional em Saúde; EAD: Educação a distância; TCR: Trabalho de Conclusão de Residência.

Observa-se que um considerável número de profissionais participou da COREMU (25\%) e da Comissão de Ensino (59\%). Como nesses espaços concentram-se os níveis de gestão, de decisão e de condução do ensino, tem se mostrado importante estimular essa participação para que a experiência na residência seja vivenciada de forma mais integral por um maior número de profissionais.

Ademais, é importante sinalizar que $45,2 \%$ dos entrevistados relatou que orienta ou orientou residentes na construção no Trabalho de Conclusão da Residência (TCR), enquanto o número de mestre (requisito mínimo para ser orientador) corresponde a 70,9\% do corpo de profissionais de Serviço Social. Esse valor é influenciado, principalmente, pelo número de residentes egressos e pela escolha do residente pela temática para o desenvolvimento do trabalho e consequente fixação no campo de prática no segundo ano de residência.

Sobre as múltiplas atividades desenvolvidas, os assistentes sociais têm participado como docentes no eixo específico $(90,4 \%)$, sendo que mais da metade já atuou como coordenador desses módulos (54,9\%), o que demonstra uma participação ativa dos profissionais e em número significativo na coordenação de práticas de docência do eixo

pesquisa que fomentem a produção de projetos de pesquisa e projetos de intervenção voltados à produção de conhecimentos e de tecnologias que integrem ensino e serviço para a qualificação do SUS (INSTITUTO NACIONAL DE CÂNCER JOSÉ ALENCAR GOMES DA SILVA, 2015). 
específico da categoria profissional. Quanto aos módulos do eixo transversal, destaca-se que: $45,1 \%$ atua (ou atuou) como docente; $16,1 \%$ dos profissionais atuam ou atuaram, considerando um espaço relevante na residência; e os assistentes sociais têm muito a contribuir, sobretudo com as temáticas de amplo conhecimento da categoria. A proposta principal da residência consiste na atuação multiprofissional, objetivando veementemente a integralidade da formação - no eixo transversal são 7 categorias que participam e mais outros profissionais envolvidos, o que exige uma relação integrada não apenas entre os discentes, mas também entre os docentes que compartilham a coordenação dos módulos. Esse tema também foi abordado no grupo focal:

É muito importante, não só para o usuário e para esse residente, mas também para as equipes. Coloca a equipe para refletir e buscar essa integração, que é algo que também tem tudo a ver com o nosso Projeto Ético Político (Entrevistada 3).

A sobrecarrega de trabalho dos profissionais, associada às múltiplas funções desempenhadas pelos preceptores, foi ratificada durante o grupo focal:

Eu tenho que organizar não sei quantos atendimentos e me organizar enquanto preceptor. Mas isso é um ponto inerente a prática, é a formação em serviço. É uma coisa que eu realizo meio que no mecânico, mas tenho que concatenar isso sem trazer prejuízo para ele (residente), mas ao mesmo tempo eu sei que pode trazer, sabe? Eu, pelo menos, tenho muito essa tensão (Entrevistada 2).

A extensa carga horária de 60 horas da residência implica na intensificação do trabalho dos preceptores, especialmente para uma categoria que deveria ter carga horária de 30 horas semanais, conforme estabelecido na legislação em 2010 (BRASIL, 2010).

O INCA atende muita gente e a gente precisa também dar conta dessa demanda da residência. A gente não tem essa carga horária exclusiva para o ensino e mesmo que a gente idealize isso, eu fico pensando: se é uma formação em serviço, essa carga horária em algum momento vai ser de fato dividida? São coisas que a gente vai discutindo (Entrevistada 3)

O documento lançado em 2017 pelo CFESS/CRESS Residência em Saúde e Serviço Social: subsídios para reflexão ressalta que, mesmo que se defina a proporcionalidade entre atividades teóricas, teórico-práticas e práticas, a manutenção das 60 horas semanais, que por vezes representa a precarização do trabalho, ultrapassa a carga horária de funcionamento dos serviços (CONSELHO FEDERAL DE SERVIÇO SOCIAL, 2017).

Nessa esteira de pensamento, Rodrigues (2016) afirma que no espaço das residências multiprofissionais, "[...] sessenta horas semanais implica a intensificação do trabalho e segue contrária à luta mais geral dos trabalhadores quanto à carga horária de 30 horas semanais". A autora destaca que é urgente a necessidade de discutir essa problemática nos espaços organizativos e instâncias legais dos Programas de Residência para a construção de outros marcos legais que avancem na perspectiva de revisão desta extensa carga horária.

Essa questão relacionada à disparidade da carga horária dos preceptores e dos residentes tem se apresentado de forma contundente nos programas de residência em todo país, não sendo diferente no caso estudado. 


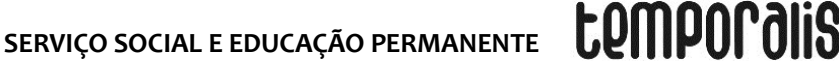

A gente precisa se desdobrar em dois, em três, em dez para conseguir dar conta das atividades assistenciais e das atividades de ensino e esse é o grande complicador da nossa rotina. A gente não conseguiu que a instituição percebesse o ensino com a importância que ele tem (Entrevistada 3).

A gente faz ensino muito pelo estímulo, pelo nosso projeto, mas não temos uma carga horária. Eu acho que isso pesa. É paradoxal essa situação. Que apesar de estar lá na sua missão, no tripé assistência-ensino-pesquisa, eu acho que se deve estimular também o ensino dentro das metas institucionais, eu acho que seria muito favorável (Entrevistada 3).

As falas supracitadas dizem respeito não somente às dificuldades que os preceptores encontram em relação à divisão de carga horária, mas principalmente, em relação às suas percepções sobre limitações da instituição em definir não apenas uma carga horária própria para o desenvolvimento das atividades de ensino e pesquisa, mas também de definir mecanismos institucionais que contemplem essas ações. $O$ que se revela uma contradição nessa instituição de Ciência \& Tecnologia.

Outro importante desafio destacado pelos participantes é a relação preceptor-residente nos processos de ensino-aprendizagem.

Acho que se há algum desafio, ele está no campo das relações pessoais, que não é exclusividade de relação residente e preceptor, residente e tutor [...]. Diferentes formas de visualizar o mundo, desafios geracionais. Tem de fato diferenças geracionais de formação, tem perspectivas e visões do mundo, mas isso eu não vejo como algo negativo, eu vejo como algo desafiador (Entrevistada 2).

Para Silva, Monteiro, Santo, Melo e Estalino (2012), é na área de Educação em Saúde, entendida como campo privilegiado para a construção de saberes e práticas de educação em serviço, que se estabelecem as relações sociais cotidianas entre os profissionais de saúde no âmbito institucional. $E$, nesse cotidiano, o processo de formação é atravessado por diversos campos de tensões, de correlação de forças, tendo em vista que a saúde também é um espaço contraditório de disputa. Dentre eles, destacaram-se a conjuntura atual e as diferentes perspectivas de projetos presentes na saúde:

[...] essa formação tem embates com a realidade, tendo em vista os projetos societários diferentes do que a gente propõe em nosso Projeto Ético Político (Entrevistada 2).

Castro (2013) afirma que “[...] no âmbito do Serviço Social, a residência deve ser pensada no sentido de aprofundar a reflexão sobre as relações do Estado, a política de saúde e a inserção dos assistentes sociais na área" (CASTRO, 2013, p. 353), devendo, portanto, suscitar reflexões acerca do trabalho em saúde diante da realidade social, sem desconsiderar a dimensão da totalidade e sem perder de vista os valores defendidos pelo Projeto Ético Político.

Apesar desses desafios, os participantes do grupo focal ressaltaram as possibilidades para o desenvolvimento desse projeto, destacando-se o comprometimento da equipe:

[...] é a potência e o desejo da equipe, né? Em todas as cinco unidades que nós temos, a equipe tem muita potência, muito desejo de elaborar o ensino. É um envolvimento imenso, assim, a gente pode estar acertando em alguns momentos e errando em 
outros. Mas no Serviço Social essa potência se torna uma capilaridade muito rápida. Para eu estar aqui a minha equipe está me dando todo o respaldo para eu estar aqui. Isso é muita potência, porque a gente gosta muito de estar nesse espaço, sabe? A gente coloca a cara a tapa para levar, mas a gente não perde essa potência. É um contraponto muito grande ao paradoxo. A gente tem a formação profissional muito enraizada na nossa profissão. A gente precisa formar pessoas críticas (Entrevistada 2 , grifo nosso).

Outrossim, destacamos nessa fala o empenho dos profissionais em garantir o ensino na área, demonstrando o compromisso ético-político com a formação dos assistentes sociais residentes. No contexto da precarização das condições de trabalho na área da saúde, há uma luta pela ampliação dos concursos públicos e, no INCA, essa é uma demanda dos trabalhadores.

Então ter como meta institucional e dar visibilidade ao que a gente faz, não só na residência, mas no ensino geral: visita técnica, estágio optativo, fellow, atualização e etc. Por que parece que a gente está em um submundo, né. A gente faz, mas escondido. Cadê a visibilidade? 'Botar' nas metas do Ministério, para gente brigar por mais profissionais (Entrevistada 1).

Na fala supracitada, observamos uma preocupação do profissional quanto à falta de visibilidade do ensino nas atividades em saúde, sobretudo o reconhecimento da residência como estratégia importante para a formação de trabalhadores da saúde, contemplando a educação permanente como parte indissociável do exercício profissional.

No caso específico da atuação dos preceptores no espaço da Residência Multiprofissional, destaca-se o cotidiano como uma categoria importante de análise. Segundo Torres (2015), trata-se do espaço privilegiado da intervenção profissional, bem como de reconhecimento da materialização das relações sociais. Para a autora, é exatamente no cotidiano que se identificam as contradições, as lutas pelo poder, as vias de organização e de resistência.

Por isso, o modo como os assistentes sociais compreendem o cotidiano em que estão inseridos dentro das instituições (sob um ponto de vista analítico e interventivo) deve estar fundamentado na matriz crítica, sem desconectar as suas ações e inserções enquanto trabalhadores que estão imersos em uma política social e que cotidianamente atuam diante das expressões da questão social que afetam todos os trabalhadores. Logo, cabe aos assistentes sociais reconhecerem o modo como se materializam essas expressões nos espaços sócio-ocupacionais nos quais se inserem como profissionais assalariados, uma vez que, esse movimento reflexivo e crítico da análise social pode possibilitar seu reconhecimento, enquanto classe trabalhadora diante do cenário capitalista.

Portanto, o desafio que se coloca é o de perceber os dilemas, limites, desafios e avanços existentes no trabalho coletivo da saúde e, com isso, refletir se de fato a formação em saúde tem sido desenvolvida em consonância com o projeto ético-político da profissão, com as diretrizes da Educação Permanente e com os princípios da Reforma Sanitária. 


\section{CONSIDERAÇÕES FINAIS}

A discussão sobre formação em saúde, a partir da experiência das residências, contribui para a reflexão sobre o exercício profissional, de forma crítica, propositiva e interativa com outras categoriais profissionais, tendo em vista o desafio da interdisciplinaridade e a defesa dos princípios da Reforma Sanitária na saúde pública.

O debate sobre a formação profissional é relevante em demasia na conjuntura atual, especialmente pelo fato de construir possibilidades na reorganização e construção coletiva do processo de trabalho e luta na saúde, impulsionando a qualificação dos serviços prestados. Destarte, é necessário que se invista numa política de formação permanente e nas condições de trabalho para o exercício da tutoria, preceptoria, dentre outras funções na residência; entendendo que a constante atualização teórica contribui para uma reflexão crítica do profissional e fornece subsídios para mediações necessárias, a fim de que não se ratifique um discurso muito comum de que na prática a teoria é outra.

Os participantes da pesquisa destacaram questões sobre os limites e desafios para a materialização das práticas do ensino, apresentando algumas das tensões existentes no projeto das residências, pois ser preceptor, orientador, coordenador e/ou tutor pressupõe dispor de uma carga horária específica para o desenvolvimento de tais funções. As falas apresentadas justificam os dados obtidos na análise do perfil dos preceptores, que contribui para a compreensão ampliada acerca da política de saúde num contexto de intensa precarização. Por isso, é necessário aprofundar o entendimento sobre a importância das residências para a atuação e formação dos assistentes sociais, sem desvinculá-la do contexto mais amplo da saúde pública brasileira, na qual o projeto privatista tem disputado espaço em detrimento do SUS; reconfigurando, assim, os postos de trabalho nas políticas sociais. Essa realidade não é vista somente na saúde, mas em outras políticas setoriais, em que se observa uma intensa precarização e terceirização dos serviços, tendo em vista os projetos societários em disputas.

A utilização dos métodos de pesquisa quantitativos e qualitativos permitiu reflexões acerca dos processos de formação dos preceptores e das suas percepções diante das próprias experiências nesse processo de ensino.

Os objetivos propostos foram atingidos através dos dados e das análises que evidenciaram a problemática existente nas condições de trabalho dos profissionais, muito visíveis nas falas destacadas no grupo focal que apresentaram principalmente os aspectos ligados às múltiplas funções da atuação na instituição e a elevada carga horária de trabalho.

Todavia, por meio dos resultados foi possível perceber que apesar dos limites, o espaço da formação em serviço é também um local de luta e de transformação, com destaque para a importância da troca de saberes na relação preceptor e residente. Com isso, os resultados destacam que a educação permanente promove o amadurecimento profissional, não apenas dos residentes, mas de todos os sujeitos envolvidos no processo.

Entende-se que o processo de educação permanente deve ser reconhecido no espaço do PRMO a partir das suas potencialidades, limites e desafios diante de um cenário contraditório, constantemente influenciado pelos aspectos políticos e econômicos da 
sociedade. Nesse sentido, devemos pensar em estratégias educacionais que defendam os princípios da Reforma Sanitária, realizando as articulações necessárias para a interlocução das diversas áreas de conhecimento, através de espaços de diálogo e socialização de informações, tendo a direção do Projeto Ético-Político da profissão como norte.

\section{REFERÊNCIAS}

BARDIN L. Análise de conteúdo. Lisboa: Edições 7/ LDA, 2009.

BRASIL. Ministério da Saúde. Portaria de Consolidação $\mathbf{n}^{\circ}$ 2, de 28 de setembro de 2017, consolidação das normas sobre as políticas nacionais de saúde do Sistema Único de Saúde. Brasília (DF), 2017. Disponível em:

<http://bvsms.saude.gov.br/bvs/saudelegis/gm/2017/prc0002_03_10_2017.html> Acesso em: 20 mar.2018.

BRASIL. Comissão Nacional de Residência Multiprofissional em Saúde. Resolução CNRMS $\mathrm{n}^{\circ} 2$, de 13 de abril de 2012, Dispõe sobre Diretrizes Gerais para os Programas de Residência Multiprofissional e em Profissional de Saúde. Diário Oficial da União; Poder Executivo, Brasília (DF), 16 abr. 2012. Seção I, p.24-25. Disponível em:

<http://portal.mec.gov.br/index.php?option=com_docman\&view=download\&alias=15448resol-cnrms-n2-13abril-2012\&ltemid=30192>. Acesso em: 16 fev.2018

BRASIL. Presidência da República. Lei n 12.317, de 26 de agosto de 2010. Acrescenta dispositivo à Lei ${ }^{\circ} 8.662$, de 7 de junho de 1993, para dispor sobre a duração do trabalho do Assistente Social. Disponível em: <http://www.planalto.gov.br/ccivil_03/_ato20072010/2010/lei/l12317.htm>. Acesso em: 20 jul. 2018.

BRASIL. Ministério da Educação. Resolução n. 1, de 21 de julho de 2015. Dispõe sobre a organização, o funcionamento e as atribuições da Comissão de Residência Multiprofissional (COREMU) das instituições que ofertam programas de residência em área profissional da saúde na modalidade multiprofissional e uniprofissional. Diário Oficial da União, Brasília (DF), n. 138, 22 jul. 2015. Disponível em:

<http://pesquisa.in.gov.br/imprensa/jsp/visualiza/index.jsp?jornal=1\&pagina=16\&data=22/0 7/2015>. Acesso em 27 nov.2018.

BRASIL. Ministério da Educação. Ministério da Saúde. Portaria interministerial MEC/MS N 1.077, de 12 de novembro de 2009, revoga a Portaria interministerial MEC/MS No 45 , de $12-$ 01-2007 alterada pela Portaria interministerial MEC/MS N 1.224, de 03-10-2012, Dispõe sobre a Residência Multiprofissional em Saúde e a Residência em Área Profissional da Saúde, e institui o Programa Nacional de Bolsas para Residências Multiprofissionais e em Área Profissional da Saúde e a Comissão Nacional de Residência Multiprofissional em Saúde. Diário Oficial da União; Poder Executivo, Brasília (DF), 13 nov. 2009. Seção I, p.7. Disponível em: <http://portal.mec.gov.br/index.php?option=com_docman\&view=download\&alias=15462por-1077-12nov-2009\&Itemid=30192>. Acesso em: 20 fev. 2018. 
BRASIL. Presidência da República. Lei n 11.129, de 30 de junho de 2005. Institui o Programa Nacional de Inclusão de Jovens - Pro Jovem; cria o Conselho Nacional da Juventude - CNJ e a Secretaria Nacional de Juventude; altera as Leis $\mathrm{n}^{\circ} \mathbf{s 1 0 . 6 8 3}$, de 28 de maio de 2003, e 10.429, de 24 de abril de 2002; e dá outras providências. Disponível em: <http://www.planalto.gov.br/ccivil_03/_Ato2004-2006/2005/Lei/L11129.htm>. Acesso em: 20 jul. 2018.

BRAVO, M. I. S.; MATOS, M. C. Reforma Sanitária e Projeto Ético Político do Serviço Social: elementos para o debate. In: BRAVO, M.I.S. et al. Saúde e Serviço Social. 2. ed. São Paulo: Cortez, 2006.

CAROTTA, F.; KAWAMURA, D.; SALAZAR, J. Educação Permanente em Saúde: uma estratégia de gestão para pensar, refletir e construir práticas educativas e processos de trabalhos. Saúde e Sociedade, v. 18, supl.1, 2009.

CASTRO, M. M. C. Formação em Saúde e Serviço Social: as residências em questão. Textos \& Contextos, Porto Alegre, v. 12, n. 2, jul./dez. 2013. p. $349-360$.

CHALUB, Tânia; SKABA, Márcia Fróes. A construção do conhecimento em Serviço Social em oncologia: a contribuição do curso de especialização do INCA. Revista Brasileira de Cancerologia, v. 49, n. 1, p. 39-46, 2003.

CONSELHO FEDERAL DE SERVIÇO SOCIAL. Residência em Saúde e Serviço Social: subsídios para reflexão. Brasília, DF: CFESS, 2017. (Série: Trabalho e projeto profissional nas políticas sociais).

CONSELHO FEDERAL DE SERVIÇO SOCIAL. Política de Educação Permanente do conjunto CFESS/CRESS. Brasília, DF: CFESS, 2012.

CONSELHO FEDERAL DE SERVIÇO SOCIAL. Parâmetros para atuação de Assistentes Sociais na política de saúde. Brasília, DF: CFESS, 2010. (Série: Trabalho e projeto profissional nas políticas sociais).

GIL, A. C. Métodos e Técnicas de Pesquisa Social. 6. ed. São Paulo: Atlas, 2008.

GUERRA, Yolanda. Compromisso com a qualidade dos serviços à população e com o aprimoramento intelectual, na perspectiva da competência profissional: significado limites e possibilidades. In: Conselho Regional de Serviço Social (Org.). Projeto ético político e exercício profissional em serviço social: os princípios do código de ética articulados à atuação crítica de assistentes sociais. Rio de Janeiro: CRESS, 2013.

IAMAMOTO, M. V. Serviço Social em tempo de capital fetiche: capital financeiro, trabalho e questão social. São Paulo: Cortez, 2007.

INSTITUTO NACIONAL DE CÂNCER JOSÉ ALENCAR GOMES DA SILVA. Programas de Residência Multiprofissional em Oncologia e Residência em Física Médica: plano de curso. 3. ed. rev. atual. ampl. Rio de Janeiro, 2018. 108 p. 


\section{temporalis}

JOYCE HELENA MARTINS LEAL

INSTITUTO NACIONAL DE CÂNCER JOSÉ ALENCAR GOMES DA SILVA. Regimento interno da Comissão de Residência Multiprofissional do INCA Rio de Janeiro, 2015.

INSTITUTO NACIONAL DE CÂNCER JOSÉ ALENCAR GOMES DA SILVA. Regimento Geral da Coordenação de Ensino do INCA. Rio de Janeiro, 2014.

LOBATO, C. P. Formação dos trabalhadores de saúde na residência multiprofissional em saúde da família: uma cartografia da dimensão política. 2010. Tese (Doutorado em Saúde Coletiva) - Universidade Estadual de Londrina, Londrina, 2010.

MINAYO, M. C. S. (Org.). Pesquisa Social: Teoria, método e criatividade. 19. ed. Petrópolis: Vozes, 2001.

MONTEIRO, M. Serviço Social na Residência Multiprofissional. Seminário, A Saúde e a Conjuntura Contemporânea - desafios para o Serviço Social ,2015, Rio de Janeiro. Anais..., Rio de Janeiro, 2015.

RODRIGUES, F. T.; Residências Multiprofissionais em Saúde: formação ou trabalho?. Serv. Soc. \& Saúde, Campinas, v.15, n. 1, p. 71-82, jan./jun. 2016.

SILVA, L. C.; BROTTO, M. E. Residência Multiprofissional em Saúde e Serviço Social: dilemas na formação e trabalho profissional. Em Pauta, Rio de Janeiro, v. 14, n. 37, p. 126149, 2016.

SILVA, L. B.; MONTEIRO, M. V. C; SANTO, M. C. B.; MELO, F. R.; ESTALINO, E. S. O ServiçO Social na Residência Multiprofissional em Oncologia no Instituto Nacional do Câncer INCA. Serv. Soc. \& Saúde, Campinas, v. 11, n. 1, p. 51-66, jan./jun., 2012.

TORRES, M. O trabalho socioeducativo desenvolvido pelo assistente social: concepções e atividades desenvolvidas. Revista Libertas, Juiz de Fora, v. 14, n. 2. 2014. 